\title{
When Job Ads Turn You Down: How Requirements in Job Ads May Stop Instead of Attract Highly Qualified Women
}

\author{
Lien Wille $^{1}$ - Eva Derous ${ }^{1}$ \\ (C) Springer Science+Business Media, LLC, part of Springer Nature 2017
}

\begin{abstract}
Qualification-based targeted recruitment strategies aim to increase the number of qualified applicants from certain social groups, such as women. Typically, such strategies assume that individuals are more likely to apply for a job when they possess the requirements needed for that job. However, how job seekers react to requirements in job ads is not often considered and is explored in the present study. In two experimental studies with Belgian university students we investigated whether person requirements about which women have negative meta-stereotypes (like the trait of emotionality) and the way such requirements are formulated in job ads (i.e., using trait-like adjectives, "You are calm/not nervous," or behavior-like verbs, "You remain calm in stressful situations") affected women's job attraction and decision to apply. A repeated measures ANOVA showed that job attraction was lower if women held negative meta-stereotypes about required personality traits in job ads (Study 1; 218 women; $M_{\text {age }}=23.44$ years, range $=21-42 ; 97 \%$ ethnic majorities). Moreover, qualified women applied to a lesser extent if a negatively meta-stereotyped trait was worded in a trait-like way than when it was worded in a behavior-like way (Study 2; $n=183$; $M_{\text {age }}=23.68$ years, range $=21-44 ; 58 \%$ women; $97 \%$ ethnic majorities). A practical implication is that recruiters should be sensitive to how they formulate job ads if they wish to attract a highly qualified and gender-diverse applicant pool.
\end{abstract}

Keywords Gender $\cdot$ Job advertisement $\cdot$ Job attraction $\cdot$ Application decision $\cdot$ Targeted recruitment

In many Western societies women are still underrepresented in the labor market, suffer lower hiring opportunities, and earn less than men do for equal work (European Commission 2016). Gender bias in recruitment and selection has been argued as one of the factors explaining women's overall lower labor market position (Bosak and Sczesny 2011; Cundiff and Vescio 2016; Güngör and Biernat 2009; Latu et al. 2015), and researchers have suggested qualification-based targeted recruitment to reduce adverse impact in assessment (Ryan and Tippins 2004).

Qualification-based targeted recruitment strategies (Newman et al. 2013) aim to increase the number of qualified applicants from social groups that suffer overall weaker labor market positions, such as ethnic minorities and women.

Lien Wille

Lien.Wille@UGent.be

1 Department of Personnel Management, Work and Organizational Psychology, Ghent University, Henri Dunantlaan 2, 9000 Ghent, Belgium
Typically, such strategies assume that individuals from these groups are more likely to apply for a job when they are qualified for that position (i.e., they possess the person requirements for the job; Newman and Lyon 2009; Stevens and Szmerekovsky 2010). However, surprisingly little is known about how (underrepresented) individuals perceive, experience, and react to person requirements mentioned in job advertisements (Born and Taris 2010; Newman and Lyon 2009).

Imagine, for example, a job ad requiring emotional stability for a job and women job seekers who believe that recruiters typically consider women to be highly emotional. Will women apply for a job that specifies "emotional stability" as a person requirement? Required traits might be perceived as being stereotypical for one's social group and may thus elicit negative perceptions and reactions among job seekers. Because women are often still negatively stereotyped in the labor market (Cundiff and Vescio 2016; Latu et al. 2015), women may expect that recruiters hold negative stereotypes regarding them about the person requirements for which organizations are looking and specify in their job ads (i.e., negative metastereotypes; see Owuamalam and Zagefka 2011; Vorauer et al. 
1998). Hence, qualification-based targeted recruitment could constrain highly qualified women job seekers from applying.

The present paper adds to the literature on targeted recruitment by examining the boundary conditions of qualificationbased targeted recruitment and its effectiveness for women job seekers. By means of two experimental studies, we investigate how women job seekers' attraction to jobs and decisions to apply are influenced by person requirements presented in job ads. Building on the theory of symbolic attraction (Highhouse et al. 2007), we first consider targeted recruitment initiatives (including qualification-based targeted recruitment) for women job seekers. Subsequently, we discuss how person requirements (i.e., negatively vs. positively meta-stereotyped personality traits) and their wording (i.e., trait-like vs. behavior-like) may affect women job seekers' job attraction (Study 1) as well as their application decisions (Study 2).

\section{Symbolic Attraction}

According to the theory of symbolic attraction (Highhouse et al. 2007), job attraction can be explained by cues or signals that organizations send through recruitment tools, the (symbolic) inferences made by job seekers based on these cues, and job seekers' social identity concerns related to these inferences. For instance, organizations with equal opportunity statements in their job ads (i.e., cue) may be perceived as organizations that value diversity (i.e., symbolic inferences), which in turn may have a greater effect on job seekers concerned about their social-economic background and weaker labor market position (i.e., social identity concerns). Symbolic inferences would thus have a stronger effect on job attraction when job seekers' social identity concerns related to these inferences are high. Further, it is assumed that job seekers' attitudes would be in accordance with their social identity (Highhouse et al. 2007; Leary and Allen 2011) and their sense of self to preserve a positive social identity (i.e., social identity theory, Tajfel and Turner 1986). Job seekers' perceived job attraction would hence increase as the fit between their social identity, on the one hand, and the organization (e.g., recruitment initiatives), on the other hand, increases. Supporting this idea, Ashfort and Mael (1989) showed that job seekers were more attracted by organizations that are congruent with their social identity.

Two targeted recruitment strategies that seem to fit with women's social identity are the portrayal of gender diversity and the inclusion of equal employment opportunity statements in job ads (Avery and McKay 2006). For instance, picturing a woman and a man compared to only a man (Bosak and Sczesny 2008), as well as using extensive rather than minimal equal employment statements (McNab and Johnston 2002), positively affect women's perceived job suitability and organizational attraction (see also Windsheid et al. 2016).
Although adding diversity cues (like gender-diverse pictures) to job ads might attract more women, recent research also showed that targeting both job seekers' surface-level (e.g., demographic characteristics like gender) and deep-level attributes (i.e., traits, abilities, and values) might be more successful than only targeting demographic characteristics in predicting job seekers' job attraction (Casper et al. 2013; Wayne and Casper 2016). Casper et al. (2013), for instance, found that advertising human resource policies (e.g., work-family balance) was more effective for targeting job seekers whose values correspond with the firm's policies (e.g., family values) than for targeting surface level demographics (e.g., job seekers' parental status). Newman et al. (2013) and Newman and Lyon (2009) also pointed out that qualification-based targeted recruitment strategies might be most effective because they directly influence the quality of applicant pools (i.e., deep-level attributes like traits). For instance, Newman and Lyon (2009, p. 305) mentioned that “...if jobs are described as needing conscientious applicants, individuals who possess those qualities will be more likely to apply for the position." In line with this point, Stevens and Szmerekovsky (2010) found that the higher job seekers' conscientiousness and openness to experience, the more attracted they are to job ads listing those traits as person requirements.

\section{Meta-Stereotyped Traits}

Remarkably, how job seekers feel about person requirements in job ads is not considered in the literature on qualificationbased targeted recruitment. For instance, if women job seekers feel at ease about the requirements specified in the job ad, they might indeed apply. Yet, job seekers could also feel threatened by certain personality requirements, which may constrain them from applying, despite being qualified for these traits. Research indeed showed that women job seekers hold metastereotypes regarding some personality traits (Owuamalam and Zagefka 2011). Meta-stereotypes reflect one's beliefs about what out-group members think of his/her own ingroup members and they are mostly negative in valence (Vorauer et al. 1998). Examples of negative metastereotypes women job seekers hold are that male recruiters find women fearful, insecure, and over-sensitive (Owuamalam and Zagefka 2011).

In the early recruitment stage, job seekers typically have limited information about jobs and organizations so that they may infer such information from job ads (Barber 1998; Rynes 1991). Because verbal cues and anticipated evaluations, as provoked by recruitment and selection situations, can activate job seekers' meta-stereotypes (Vorauer et al. 1998; Vorauer et al. 2000), job seekers may infer that they will be assessed in accordance with negative stereotypes about them when job ads require a trait about which they hold negative meta- 
stereotypes (Vorauer et al. 1998). Schuster and Martiny (2017), for instance, found that women experienced more social identity threat in a situation that evoked negative metastereotypes than in a situation that did not evoke negative meta-stereotypes (like when no or positive meta-stereotypes were activated; see also Cheryan et al. 2009).

Because experiencing social identity threat may cause negative outcomes (see Emerson and Murphy 2014, for an overview), women job seekers (especially highly qualified ones) may feel less attracted to jobs if job ads stress a negatively meta-stereotyped trait. Women's perceived job attraction would, however, not be negatively influenced if job ads stress a personality trait about which they do not hold negative meta-stereotypes (e.g., when meta-stereotypes are positive). Indeed, such job ads would not be perceived as a threat to their social identity. Building on the theory of symbolic attraction and in line with the literature on meta-stereotyping, we therefore hypothesize that women job seekers will be less attracted to job ads that stress a personality trait about which they hold negative meta-stereotypes than to job ads that stress a trait about which they do not hold negative meta-stereotypes (Hypothesis 1).

\section{Wording of Traits}

Not only the kind of personality requirements but also how organizations formulate these requirements should be considered. Personality traits may, for instance, be formulated using either adjectives (i.e., a trait-like wording) or verbs (i.e., a behavior-like wording), which reflects an essentialism (e.g., being emotional) versus constructionist (e.g., displaying emotional behavior) distinction, respectively. Each of these type of wordings may subtly signal different messages about how recruiters evaluate applicants (see Rubini and Menegatti 2008; Volpone et al. 2013), hence possibly eliciting different levels of social identity threat and job attraction within the job seeker. Born and Taris (2010), for instance, showed that women job seekers were less attracted to a masculine than to a feminine job profile when the profiles were worded in a trait-like way, but that this difference disappeared when those profiles were worded in a behavior-like way.

The linguistic category model (Semin 2008; Semin and Fiedler 1991) indeed posits that the wording of a person profile may affect how that profile is perceived and evaluated. Social psychologists have shown that verbs and adjectives play a central role in person perceptions: Verbs are considered as devices that describe more concrete behaviors (e.g., support) or psychological states (e.g., needing support), whereas adjectives (e.g., supportive) are devices that describe more abstract and stable psychological dispositions. According to the linguistic category model (Semin and Fiedler 1991), verbs and adjectives are organized along a dimension of concreteness-abstractness, with verbs being more on the concrete side and adjectives being more on the abstract side of the dimension. If person requirements (like traits) are presented using adjectives (e.g., "The organization expects calm workers"), one may perceive this information as revealing more about a person's stable nature than if the same information is presented in terms of more concrete behaviors using verbs (e.g., "This organization expects you to keep calm in stressful situations").

A behavior-like wording of a trait about which women hold meta-stereotypes puts this trait in a behavioral/ situational context and may signal to women job seekers that recruiters will pay more attention to how they behave in a concrete situation (e.g., displaying emotional behavior) than to how they really are (e.g., being emotional). Because a trait-like wording, on the other hand, suggests stable person characteristics, women job seekers may get the impression that recruiters will base their assessment on their stereotypes about women's presumed nature (what they are) rather than their behavior (how they might behave). Women job seekers may hence perceive a trait-like wording of person requirements about which they hold negative meta-stereotypes (compared to a behavior-like wording) as a bigger threat to their social identity and as such feel less attracted to the job if a negatively meta-stereotyped trait is worded in a trait-like rather than in a behavior-like way (i.e., the moderation effect of wording; Hypothesis 2).

\section{Study 1}

Building on the theory of symbolic attraction, the literature on meta-stereotyping, and predictions from the linguistic category model, Study 1 investigated whether women job seekers are less attracted to job ads when the required trait in the job ad is one about which they hold negative meta-stereotypes (Hypothesis 1) and whether the wording of this trait as traitlike or behavior-like moderated that effect (Hypothesis 2).

\section{Method}

\section{Participants}

Participants of Study $1(n=218)$ were all women job seekers at a large Belgian university in their final year of a Master's program (age: $M=23.44$ years, $S D=3.02$, range $=21$ 42 years; 211 or $96.80 \%$ ethnic majorities) who were actively looking for a job or were going to do so in the future (i.e., 200 or $91.70 \%$ already consulted job ads and 165 or $75.70 \%$ already reacted to job postings). 


\section{Design}

Study 1 applied a 2 (Meta-stereotyping: negative vs. positive) $\times 2$ (Wording: trait-like vs. behavior-like) mixed-subjects design with meta-stereotyping as the between-subjects variable (i.e., participants were presented the negatively or the positively meta-stereotyped trait) and wording as the withinsubjects variable (i.e., the negatively/positively metastereotyped trait was worded trait-like or behavior-like). Job attraction was the dependent variable. The $2 \times 2$ design reflects four different conditions (or job ads), each reflecting one of the following cells: (a) a job ad with a personality requirement about which women job seekers held negative meta-stereotypes and that was formulated in a trait-like way ("You are calm/not nervous"), (b) a job ad with a personality requirement about which women job seekers held positive meta-stereotypes and that was worded in a trait-like way ("You are extraverted"), (c) a job ad with a personality requirement about which women job seekers held negative meta-stereotypes and that was worded in a behavior-like way ("You keep calm in stressful situations"), and (d) a job ad with a personality requirement about which women job seekers held positive meta-stereotypes and that was worded in a behavior-like way ("You enjoy interacting with others").

\section{Development of Study Materials}

Before conducting the main study, study materials were developed. First, we conducted a pilot test $(n=42$; age: $M=$ 21.74 years, $S D=1.59$, range $=21-30$ years; 39 or $92.90 \%$ ethnic majorities; work experience: $M=14.12$ months, $S D=$ 25.18 , range $=0-150$ months) to investigate personality traits about which women hold negative and positive metastereotypes to include in the job advertisements. Personality traits were based on the HEXACO model of personality, which is a well-known and empirically supported personality model consisting of six personality traits (i.e., extraversion, agreeableness, emotionality, conscientiousness, openness to experience, and integrity; see Ashton et al. 2004; de Vries et al. 2009; Lee and Ashton 2004, for more information), and which is often used for personnel selection. Each HEXACO trait is characterized by several adjectives (e.g., emotional and fearless for the trait emotionality; Lee and Ashton 2008).

Participants first indicated to what extent they believed that men find women extraverted, agreeable, emotional, conscientious, open to experience, and having integrity (i.e., metastereotype; see Kamans et al. 2009). They rated the 30 highest loading adjectives per trait on a 5-point Likert-type scale from 1 (strongly disagree) to 5 (strongly agree). A trait was considered a meta-stereotyped trait when the mean score over the 30 adjectives was 3 or higher (with a higher score indicating that women had more meta-stereotypes regarding the trait). In the second part of the pilot study, participants reported on a 5point Likert scale if they perceived those meta-stereotypes as negative or positive (i.e., the perceived valence of meta-stereotypes). An example item is "Some men find women emotional. I (as a woman) consider this idea that men might have about women as.....," with a response scale from 1 (very negative) to 5 (very positive). A higher score hence indicated that women perceived the meta-stereotypes as more positive. The results of this pilot study showed that the trait emotionality $(M=2.72, S D=.21)$ was considered a significantly more negatively meta-stereotyped trait than was the trait extraversion $(M=3.23, S D=.22), t(24)=11.12, p<.001$. Moreover, (a) the valence of the trait emotionality was rated significantly below the midpoint of the scale (i.e., 3), $t(24)=-6.77$, $p<.001$, and (b) the valence of the trait extraversion was rated significantly above that midpoint, $t(26)=5.08, p<.001$. Therefore, emotionality and extraversion were selected for the conditions negatively meta-stereotyped trait and positively meta-stereotyped trait, respectively.

Second, adjectives for the traits emotionality and extraversion were selected based on the pilot study. For the trait extraversion, the adjectives "outgoing" [in Dutch, "vlot"], "extraverted" ["extravert"], and "open" ["open"] were selected because women held positive metastereotypes about these adjectives. For the trait emotionality, the adjectives "cold-hearted" ["koelbloedig"], emotionally stable ["emotioneel standvastig"], and "calm/not nervous" ["kalm"] were selected. Although these adjectives do not appear negative in themselves, women job seekers held negative meta-stereotypes about them because they believed that men think that women are generally not cold-hearted (i.e., worried), not emotionally stable (i.e., upset/neurotic), and not so calm (i.e., nervous). These beliefs (i.e., meta-stereotypes) evoke negative feelings among women job seekers.

Next, following suggested guidelines and principles adapted from Van de Vijver and Hambleton (1996), one linguistic expert translated the selected adjectives into verbs, while another expert independently back-translated the verbs into adjectives. This resulted in the following behavior-like expressions for the trait extraversion: "You can easily handle different types of people" ["Je gaat gemakkelijk om met verschillende types mensen"], "You enjoy interacting with others" ["Je geniet van de omgang met anderen"], and "You listen to other people's ideas and remarks" ["Je luistert naar de ideeën en opmerkingen van anderen"]. For the trait emotionality the following behavior-like expressions were used: "You keep a cool head and show little emotions to the outside world" ["Je houdt het hoofd koel en toont weinig emoties naar de buitenwereld toe"], "You do not get upset easily" ["Je geraakt niet snel van slag"], and "You keep calm in stressful situations" ["Je bewaart je kalmte in stressvolle situaties"]. Finally, job ads were created and tailored to participants' 
Master degrees (e.g., law) to reflect the type of jobs for which participants were actually looking on the labor market.

\section{Procedure and Measures}

Unless otherwise indicated, items were scored on a Likertscale from 1 (strongly disagree) to 5 (strongly agree). After giving their informed consent, participants were randomly assigned to the condition negatively meta-stereotyped trait (emotionality) or the condition positively meta-stereotyped trait (extraversion). Specifically, participants read two job advertisements stressing the negatively or the positively metastereotyped trait. One of the job advertisements formulated the person requirements in a trait-like way whereas the other did so in a behavior-like way (presented in a counterbalanced order; Podsakoff et al. 2003). Thus, the two job ads represented the same job and required the same personality trait, but the trait was differently formulated (trait-like vs. behavior-like).

Each job advertisement was followed by the dependent variable, namely the job attraction measure that consisted of three items adapted from van Hooft et al. (2006): "I find this job attractive", "I would like to do this job" and, "I like this job." The scores on the three items were averaged, and higher scores indicated that women job seekers were more attracted to the job. Cronbach's alpha was .93 for participants in the trait-like wording condition and .94 for those in the behaviorlike wording condition. After each job ad, as manipulation checks, participants checked the wording of the person requirements (i.e., "This organization looks for how a person behaves") and indicated the type of person requirement for which the organization was looking (i.e., "The job ad shows that this company searches for an extravert [or for an emotional] person"). Finally, participants' background characteristics (i.e., ethnicity and age) were administered. There were no missing data.

\section{Results}

\section{Preliminary Analyses}

First, we investigated the descriptive statistics and correlations of job attraction for wording (i.e., trait-like vs. behavior-like), meta-stereotyping (i.e., negative vs. positive), and participants' background characteristics (i.e., ethnicity and age). Although job attraction for the two types of wording (i.e., trait-like and behavior-like) were significantly correlated $(r=.73, p<.001)$, they still showed meaningful non-overlap $(47 \%)$. Additionally, participants' age and ethnicity were unrelated to job attraction $(r s<.14)$. Second, the randomization check was successful: Order of job ads did not affect job attraction, $F(1,216)=.05, p=.83, \eta \mathrm{p}^{2}=.00$. Third, when verbs were used $(M=3.83, S D=.87)$, traits were perceived as significantly more behaviorally determined (less stable) than when adjectives $(M=3.26, S D=1.04)$ were used, $F(1$, $217)=44.09, p<.001, \eta p^{2}=.17$. Fourth, job ads requesting individuals low on emotionality were perceived accordingly (for trait negatively meta-stereotyped: $M=4.48, S D=.73$; for trait positively meta-stereotyped: $M=4.05, S D=.84), F(1$, 216) $=16.36, p<.001, \eta \mathrm{p}^{2}=.07$. Equally, job ads seeking extraverted individuals were perceived accordingly (for the negatively meta-stereotyped trait: $M=2.40, S D=.96$; for the positively meta-stereotyped trait: $M=3.75, S D=.71), F(1$, 216) $=138.52, p<.001, \eta p^{2}=.39$.

\section{Hypothesis Testing}

Study 1 investigated whether women job seekers felt less attracted to a job if the job ad required a personality trait about which they had negative meta-stereotypes (Hypothesis 1) and whether the wording of such trait moderated the negative effect of a negatively meta-stereotyped trait on perceived job attraction (Hypothesis 2). Supporting Hypothesis 1, our results showed that job attraction was lower if a personality trait was required about which women held negative metastereotypes $(M=3.39, S D=.82)$ than if the required trait was one about which they had positive meta-stereotypes $(M=3.62, S D=.77), F(1,216)=4.29, p=.04, \eta p^{2}=.02$. Women job seekers were also less attracted to the job when the required trait was worded trait-like $(M=3.45, S D=.88)$ than when it was worded behavior-like $(M=3.55, S D=.85)$, $F(1,216)=4.27, p=.04, \eta p^{2}=.02$. Hypothesis 2 , however, was not supported because the moderating effect of wording (i.e., meta-stereotype by wording interaction) was not significant, $F(1,216)=.45, p=.50, \eta^{2}=.00$.

\section{Discussion}

Job seekers typically have limited information about jobs and organizations during the first recruitment stage, and in line with the theory of symbolic attraction (Highhouse et al. 2007), one could therefore expect that job seekers use job advertisements as signals of important aspects of the employment opportunity. Previous studies found that information in job advertisements (e.g., message content like organizational and job attributes, fit information, and employment policy information) is often used by job seekers to gather important information about potential employers (Barber 1998; Garcia et al. 2010; Purdie-Vaughns et al. 2008; Schmidt et al. 2015; Walker and Hinojosa 2013). Study 1 further investigated whether person requirements as portrayed in job ads (i.e., another type of message content) affected women's perceived job attraction because research on this type of message content is rare yet vital, for example, to understand the effectiveness of qualification-based targeted recruitment strategies.

Our findings indicate that women job seekers were less attracted to the job when a negatively meta-stereotyped trait 
was required. However, wording (i.e., trait-like vs. behaviorlike) did not moderate this effect. Women thus seemed to perceive the type of person requirements (i.e., personality trait) but not how it is communicated in the job ads as a signal, which partly supports predictions from the theory of symbolic attraction. Recent research demonstrated that messages of women applicants (as communicated in interviews) can affect recruiters' evaluations (Wessel et al. 2015). Present findings, however, show that messages of organizations (as conveyed in job ads) also may subtly influence women job seekers' attitudes through the type of person requirements communicated in job ads. Hence, organizations should be aware of the type of personality trait they require in their job ads and the potential consequences of requiring a negatively meta-stereotyped trait.

\section{Study 2}

Whereas Study 1 investigated attitudinal reactions of women job seekers to person requirements in job ads, the ultimate goal of qualification-based targeted recruitment is to increase the number of qualified job seekers who decide to apply for the job (Barber 1998; Newman et al. 2013). Organizations use job ads to inform and attract job seekers, and job seekers may self-select in or out based on the information that is communicated in the job ad. Hence, and in line with the theory of symbolic attraction (Highhouse et al. 2007), job ads might have a disparate impact on job seekers' application decisions by the way person requirements are presented to and evaluated by job seekers. The goal of Study 2 was to investigate whether the wording of a negatively meta-stereotyped trait differently affected the application decisions of qualified women and men, hence investigating adverse impact in recruitment.

Adverse impact is defined as "a substantially different rate of selection in hiring, promotion, or other employment decision which works to the disadvantage of members of a race, sex, or ethnic group" (Equal Employment Opportunity Commission 1978, section 16D; see also Tippins 2010). More generally stated, adverse impact reflects the possibility of unfairness in employment-related decisions against any subgroup (Higuera 2001). Güngör and Biernat (2009) for instance found that gender bias emerged at the earliest stage of the job-seeking process. Although research on recruitment typically does not use the notion of adverse impact (see De Corte 2011; Derous and Ryan 2012; Newman et al. 2013 for exceptions), recruitment tools may induce adverse impact in later assessment stages (Ryan and Tippins 2004) as well as suffer adverse impact themselves (De Corte 2011) if recruitment tools attract job seekers in a differential way such that certain social groups decide not to apply and are systematically excluded. We propose that job ads could have an adverse impact if information communicated in the ads systematically discourages qualified women to apply for the portrayed job.
This might result in differential application rates (i.e., the ratio of the number of qualified applicants to the total number of applicants) for women and men.

Inspired by the adverse impact literature, we applied the idea of the adverse impact ratio (i.e., the ratio of selection rates of qualified minorities to qualified majorities) to recruitment and the way the wording of person requirements in job advertisements might encourage or discourage qualified women to apply for the portrayed job. Comparable to the adverse impact ratio, we formulated the application impact ratio as the ratio of application rates of qualified women job seekers to qualified men job seekers. With regard to women job seekers' application rate, we anticipated it to be lower for a trait-like than a behavior-like wording of a negatively meta-stereotyped trait because we expected the negative effect of a negatively metastereotyped trait on qualified women's application decisions to be larger if the former wording is used. Concerning men's application rate, we anticipated it to be relatively unaffected by the wording of person requirements because metastereotypes would not apply or apply less to this group of job seekers. Therefore, we expected that the application impact ratio will be lower for job ads using a trait-like wording of a negatively meta-stereotyped personality trait than a behavior-like wording of such trait (Hypothesis 3 ).

\section{Method}

\section{Participants and Design}

Participants $(n=183)$ were all job seekers (age: $M=23.68$ years, $S D=3.42$, range $=21-44$ years; 105 or $57.40 \%$ women; 178 or $97.30 \%$ ethnic majorities) in their final year of a Master's program at a large Belgian university who were actively looking for a job or were going to do so in the future (e.g., 160 or $87.40 \%$ already consulted job ads and 141 or $77.00 \%$ already reacted to a job posting). Study 2 only presented a person requirement or a trait about which women held negative meta-stereotypes (i.e., emotionality). Study 2 specifically applied a 2 (Gender: men vs. women) $\times 2$ (Wording: trait-like vs. behavior-like) mixed-subjects design with gender as the between-subjects variable and wording as the within-subjects variable (the negatively meta-stereotyped trait or person requirement was worded in a trait-like way or in a behavior-like way). The dependent variable was application decision (i.e., application impact ratio). Study materials (pseudo job postings) were the same as in Study 1.

\section{Procedure and Measures}

As in Study 1, participants read two job advertisements (same job, different wording of the same trait, counterbalanced) that were each followed by a check for emotionality as the required 
trait and its wording. Instead of rating job attraction (Study 1), job seekers now selected the job ad for which they were going to apply (application decision). This information was used to calculate the application impact ratio (i.e., the ratio of application rates of qualified women to qualified men). Next, participants' emotionality ( $\alpha=.80)$ was measured with ten items from the HEXACO-60 (e.g., "I sometimes can't help worrying about little things"; 1 = strongly disagree to $5=$ strongly agree; Ashton and Lee 2009; de Vries et al. 2009). The scores on the ten items were averaged and were then recoded so that a higher score reflected that individuals were more qualified for the required trait (i.e., they had lower levels of emotionality). Finally, the same background characteristics as in Study 1 were administered. A minimal amount of data was missing (i.e., .89\%). The missing data were random and were addressed by deleting cases with missing data $(n=5)$ for testing the hypothesis.

\section{Application Impact Ratio}

To test if the application impact ratio is lower for job ads with a trait-like rather than a behavior-like wording of a negatively meta-stereotyped trait (Hypothesis 3), we first calculated the application rates (ARs) of qualified women and men in a similar way to how selection rates for selection tests are calculated (Zedeck 2010). That is, the number of qualified women (men) job seekers who applied for the job ad was divided by the total number (i.e., qualified + unqualified) of women (men) job seekers who applied for the job ad:

Application rate $(\mathrm{AR})=\frac{\text { number of qualified women }(\mathrm{men}) \text { applicants for the job ad }}{\text { total number of women }(\mathrm{men}) \text { applicants for the job ad }}$

(Formula 1)

In line with common practice in selection procedures (Guion 2011), women and men scoring below percentile 50 (i.e., scoring below 3.10) did not pass and were considered unqualified, whereas the others (i.e., scoring percentile 50 or higher / 3.10 or higher) did pass and were considered qualified. Subsequently, we tested whether the ARs of women and men differed significantly from each other for the trait-like and the behavior-like wording. Next, we calculated the application impact ratios (AIRs) for both the trait-like and the behaviorlike wording by dividing the AR of qualified women by the AR of qualified men:

Application impact ratio $(\mathrm{AIR})=\frac{\text { application rate qualified women }}{\text { application rate qualified men }}$

(Formula2)

Finally, we tested whether the AIRs for the trait-like and the behavior-like wording differed significantly from each other, using both the four-fifths rule (i.e., there is adverse impact when women's application rate is less than four-fifths or
$80 \%$ of men's application rate) and a z-test on the difference between proportions (Collins and Morris 2008). AIRs are proportions and z-test are one of the most commonly reported statistics to calculate significant differences in proportions when calculating adverse impact in hiring settings (Tippins 2010; see Derous and Ryan 2012, for an example).

\section{Results}

\section{Preliminary Analyses}

As in Study 1, we conducted preliminary analyses. First, randomization was successful: Order of job ads did not affect application decision, $\chi^{2}(1, n=183)=1.78, p=.18$. Second, when verbs were used $(M=3.90, S D=.85)$, traits were perceived as more behaviorally determined (less stable) than when adjectives $(M=3.30, S D=1.01)$ were used, $F(1$, $182)=41.735, p<.001, \eta p^{2}=.19$. Finally, job ads asking for individuals who score low on emotionality were perceived accordingly and there was no significant difference for traitlike wording $(M=4.45, S D=.84)$ and behavior-like wording $(M=4.40, S D=.91), t(182)=.79, p=.43$. $)$.

\section{Hypothesis Testing}

Regarding the trait-like wording, the AR of women (.31) and men (.78) differed significantly from each other $(z=-4.15$, $p<.001)$. A similar result was found for the AR of women (.41) and men (.76) for the behavior-like wording $(z=-3.44$, $p<.001)$. Applying the four-fifths rule, both the trait-like wording $(\mathrm{AIR}=.40)$ and the behavior-like wording $(\mathrm{AIR}=.54)$ show a disparate effect on women/men's application decisions because the application rates of women are less than four-fifths or $80 \%$ of men's application rates. However, and supporting Hypothesis 3, the disparate effect of the traitlike wording was significantly greater than that of the behavior-like wording $(z=-1.87, p=.03)$.

\section{Discussion}

Study 2 went beyond women job seekers' attitudes toward jobs (i.e., job attraction) by showing that qualified women job seekers applied to a lesser extent than qualified men job seekers, especially when a negatively meta-stereotyped trait was worded in a trait-like way instead of in a behavior-like way. This finding adds to the literature on targeted recruitment because it indicates that qualification-based targeted recruitment could have negative (rather than the commonly assumed positive) effects on qualified women when application decisions are investigated, which to the best of our knowledge has not previously been considered. 


\section{General Discussion}

Women are still underrepresented in the labor market (Auster and Prasad 2016; European Commission 2016), which may be partly attributed to gender bias in recruitment and selection procedures (Bosak and Sczesny 2011; Cundiff and Vescio 2016; Güngör and Biernat 2009; Latu et al. 2015). The present paper adds to this literature by investigating how recruitment initiatives may subtly discourage qualified women from applying for jobs. Indeed, whereas qualification-based targeted recruitment is put forward as a strategy to reduce adverse impact (i.e., by attracting qualified applicants from certain social groups like women; Newman et al. 2013; Newman and Lyon 2009), it somewhat overlooked the possibility of negative perceptions and reactions triggered by person requirements and their wording in job ads (Walker and Hinojosa 2013).

First, women job seekers felt less attracted to the job when the job ad required a trait about which they had negative metastereotypes (Study 1). Interestingly, Owuamalam and Zagefka (2014) also showed that activating negative meta-stereotypes lowered general employment beliefs of women. These findings are in line with Highhouse and Hoffman (2001) who mentioned that a variety of signals emitted by an organization may influence job attraction through indirect information cues. The symbolic attraction theory (Highhouse et al. 2007) and the literature on meta-stereotyping (Vorauer et al. 1998, 2000) further posit that the effects of those indirect information cues or (symbolic) inferences depend on their relevance for and the threat they entail for job seekers' social identity. In line with Purdie-Vaughns et al. (2008) who stated that cues in recruitment materials can trigger negative inferences about the judgments one may face, women may infer from a negatively meta-stereotyped trait that they would be assessed in accordance with the negative stereotypes recruiters hold about their social group. If this is perceived as a threat to their social identity, women job seekers would be less attracted to the job and refrain from applying (see Autin et al. 2013, for an example in a selection context). That is, women job seekers' attitudes and decisions would be in line with their social identity or sense of self to preserve their positive social identity (Highhouse et al. 2007; Leary and Allen 2011; Tajfel and Turner 1986). Hence, potential backfiring effects of qualification-based targeted recruitment strategies may be attributed to the threat a negatively meta-stereotyped trait may embody for women's social identity. Future research could consider underlying mechanisms of ego-threatening motives to a further extent.

Second, wording did not moderate the effect of the type of personality requirement on women's perceived job attraction, as opposed to our expectations based on the linguistic category model (Semin 2008; Semin and Fiedler 1991; Study 1). Yet, wording of person requirements did affect women's application decisions: Qualified women job seekers applied to a lesser extent when a negatively meta-stereotyped trait was communicated in a trait-like way (Study 2). The application impact ratio was indeed lower when a negatively metastereotyped trait was formulated in a trait-like rather than a behavior-like way. This result provides evidence for the subjective factors theory on job choice (Behling et al. 1968). It also underlines that the way job ads are written may have a discriminatory effect even when there is no discriminatory intent (Gaucher et al. 2011). The differential effect of wording on job attraction and application decisions may be explained by the fact that asking women to decide for which of two job ads they would apply is more impactful (less permissive) than indicating their job attraction. Asking women for their application decision might thus have made them more attentive and sensitive to the wording of the person requirements. Hence, wording might have a stronger signaling function when job seekers have to make a decision regarding job ads than when they have to rate their attraction to the job. Previous studies regarding targeted recruitment mainly focused on attraction outcomes. Application decisions are however what ultimately matters for organizations, and the current studies suggest that results found with attraction outcomes cannot automatically be generalized to application decisions. Therefore, future targeted recruitment research might focus more on how job seekers make application decisions.

Finally, notwithstanding that the application impact ratio mirrors the adverse impact ratio from selection research (i.e., the ratio of selection rates of qualified minorities to qualified majorities; Tippins 2010), a difference should be noted: In case of adverse impact in selection, it is the recruiter/ organization who disproportionally selects out women whereas in case of the application impact ratio women job seekers (disproportionally) self-select out. One could argue that a job seeker's application decision is under control of an individual and therefore should not be considered as a form of adverse impact or unfairness, which typically is considered to be under the organization's control. However, job seekers' application decisions should be considered as the result of a dynamic interplay between the job seeker and the organization (Herriot 1993), stressing the interactive and adaptive nature of recruitment practices. In addition, how organizations word their job ads is very much under the organization's control. Recruiters typically do not spend much attention to the way job ads are formulated. However, recruitment tools that systematically (though likely unintentionally) constrain women job seekers from applying might entail some form of unfairness and, therefore, should receive recruiters' full attention.

\section{Strengths, Limitations, and Future Research}

As with any study, our study has both strengths and limitations, which may inspire further research. First, as suggested 
by Highhouse and Hoffman (2001), Reeve et al. (2006), and some others (e.g., Breaugh 2008; Walker et al. 2008), we took a micro-perspective by investigating women job seekers' reactions to the person requirements mentioned in job ads. Our findings indicated that qualification-based targeted recruitment initiatives should consider what traits are required and how these traits are communicated in job ads to fully understand how women job seekers will react toward job ads. Also, whereas the qualification-based targeted recruitment literature was rather atheoretical up until now, our paper shows that it can gain from a more theoretical approach. Indeed, we used the theory of symbolic attraction (Highhouse et al. 2007), the literature on meta-stereotyping (Vorauer et al. 1998, 2000), and the linguistic category model (Semin 2008) to make predictions about how women job seekers would react to job advertisements. Hence, linking qualification-based targeted recruitment to relevant theoretical frameworks may help to improve the understanding of reactions of job seekers from social groups that suffer weaker labor market positions. Future research may combine this theoretical foundation with a more bottom-up way of generating adjectives and verbs to reflect required traits. Proceeding in a more inductive way could address the micro-level perspective to a larger extent, which might lead to stronger effects.

Second, we extended the notion of adverse impact to the recruitment stage by developing the notion of differential/ disparate impact of job ads' wording on job seekers' application decisions. Job advertisements are still an important and frequently used recruitment source by organizations that are seldom or never evaluated on the disparate impact they may have on demographic subgroups (for an illustration see De Corte 2011). Because disparate effects in recruitment may affect whether or not subsequent assessment procedures have adverse impact (Ryan and Tippins 2004), future research could investigate adverse impact in recruitment to a further extent. For instance, we compared the number of qualified applicants for job ads to the total number of applicants (both qualified and unqualified for these jobs, see Formula 1). This approach is in line with assumptions of qualification-based targeted recruitment strategies that aim to increase the number of highly qualified (compared to less qualified) applicants from certain underrepresented groups (Newman et al. 2013). As suggested by one of the reviewers, an even more stringent test would be to compare the number of qualified individuals who applied for a job ad to the total number of qualified individuals (both those who applied and those who decided not to apply) to further differentiate among qualified applicants. When considering this more stringent test, the results seemed fairly the same. Further, research might also consider other guidelines than the four-fifths rule and discuss the degree of acceptability of inter-group differences in case of the wording of job ads. The resulting insights may help to further optimize recruitment and selection procedures.
Third, we extended the targeted recruitment literature by showing the usefulness of targeted recruitment initiatives for women as a different target group than ethnic minorities, which are typically investigated in targeted recruitment literature (e.g., Newman and Lyon 2009). Note however that, although our participants were all actual job seekers, they were relatively young. This might have tempered effects because the quality of job advertisement content is expected to influence more experienced job seekers to a larger extent than their less experienced counterparts (Walker et al. 2008). Future research could investigate the potential moderating role of age and job seeking experience on effects of qualification-based targeted recruitment.

Finally, we considered one potential stigmatizing characteristic of job seekers' identity (i.e., gender). Job seekers, however, may belong to multiple social groups (e.g., a Woman of Color; see Else-Quest and Hyde 2016) and hence possess multiple stigmatizing identities (see Remedios and Snyder 2015). How job seekers with multiple stigmatizing identities experience recruitment efforts (like qualification-based targeted recruitment) is also an interesting avenue for further research that would complement research on recruiters' hiring evaluations of applicants with multiple stigmatizing identities (Derous et al. 2015).

\section{Practice Implications}

Our findings indicate that qualification-based targeted recruitment strategies may not always have their intended positive effect. Furthermore, recruiters are recommended to carefully consider the kind of message they convey in job ads when targeting women as potential applicants because personality requirements and their wording might subtly affect the overall efficacy of their job ads. When organizations have vacant positions that require traits about which women hold negative meta-stereotypes, they might more effectively reach women job seekers if they communicate those traits in a behavior-like way in their job advertisements.

Organizations may better understand the effects of their recruitment messages by calculating application impact ratios. This tool may aid organizations to monitor the impact of their job ads on job seekers. In addition, we recommend that organizations consider using mixed panels of men and women (e.g., recruiters, job incumbents) to evaluate application impact ratios and discuss requirements and their wording in job ads (e.g., using focus groups and cognitive interviewing, see Beatty and Willis 2007; Oostrom and Born 2014). Such a systematic screening of recruitment materials might help recruitment teams to more carefully separate essential from nonessential requirements and to consider the best ways in which person requirements are formulated. Indeed, organizations may be able to better target recruitment messages to desired applicants (like highly qualified women), by taking the 
perspective of those applicants. This may lead to a win-win situation for both job seekers and organizations.

\section{Conclusion}

Women job seekers' perceived job attraction was affected by the personality requirements in job ads but not by how these required traits were worded (Study 1) whereas their application decisions were affected by wording (Study 2). These findings indicate that qualification-based targeted recruitment initiatives can backfire but that organizations might attract a high quality and gender-diverse applicant pool by "getting the words right" (i.e., using a behavior-like wording). With the present paper, we hope to stimulate more research concerning the conditions under which targeted recruitment initiatives do or do not work for women job seekers and any other social groups that suffer lower labor market outcomes.

Acknowledgements The authors acknowledge Naomi Mike for her help in collecting the data.

\section{Compliance with Ethical Standards}

Conflicts of Interest The authors declare that they have no conflict of interest.

Human and Animals Rights The research involves human participants. The study was carried out in accordance with the guidelines of the 'General Ethical Protocol for Scientific Research at the Faculty of Psychology and Educational Sciences' of the Ethical Commission of the Faculty of Psychology and Educational Sciences, which is the relevant university institutional review board that considers ethical aspects. APA ethical standards were followed in the conduct of the study.

Informed Consent In accordance with the Declaration of Helsinki, participants provided informed consent prior to their participation. Only when individuals gave their informed consent, the questionnaire was presented.

\section{References}

Ashfort, B. E., \& Mael, F. (1989). Social identity theory and the organization. Academy of Management Review, 14, 20-39. https://doi.org/ $10.2307 / 258189$.

Ashton, M. C., \& Lee, K. (2009). The HEXACO-60: A short measure of the major dimensions of personality. Journal of Personality Assessment, 91, 340-345. https://doi.org/10.1080/ 00223890902935878.

Ashton, M. C., Lee, K., Perugini, M., Szarota, P., de Vries, R. E., Di Blas, L., ... De Raad, B. (2004). A six-factor structure of personalitydescriptive adjectives: Solutions from psycholexical studies in seven languages. Journal of Personality and Social Psychology, 86, 356366. https://doi.org/10.1037/0022-3514.86.2.356.

Auster, E. R., \& Prasad, A. (2016). Why do women still not make it to the top? Dominant organizational ideologies and biases by promotion committees limit opportunities to destination positions. Sex Roles, 75, 177-196. https://doi.org/10.1007/s11199-016-0607-0.
Autin, F., Branscombe, N. R., \& Croizet, J. (2013). Creating, closing, and reversing the gender gap in test performance: How selection policies trigger social identity threat or safety among women and men. Psychology of Women Quarterly, 38, 327-339. https://doi.org/10. 1177/0361684313510485.

Avery, D. R., \& McKay, P. F. (2006). Target practice: An organizational impression management approach to attracting minority and female job applicants. Personnel Psychology, 59, 157-187. https://doi.org/ 10.1111/j.1744-6570.2006.00807.x.

Barber, A. E. (1998). Recruiting employees: Individual and organizational perspectives. Thousand Oaks, CA: Sage.

Beatty, P. C., \& Willis, G. B. (2007). Research synthesis: The practice of cognitive interviewing. Public Opinion Quarterly, 71, 287-311. https://doi.org/10.1093/poq/nfm006.

Behling, O., Labovitz, G., \& Gainer, M. (1968). College recruiting: A theoretical basis. The Personnel Journal, 47, 13-19.

Born, M. P., \& Taris, T. W. (2010). The impact of wording of employment advertisements on students' inclination to apply for a job. The. Journal of Social Psychology, 150, 485-202. https://doi.org/10. 1080/00224540903365422.

Bosak, J., \& Sczesny, S. (2008). Am I the right candidate? Self-ascribed fit of women and men to a leadership position. Sex Roles, 58, 682 688. https://doi.org/10.1007/s11199-007-9380-4.

Bosak, J., \& Sczesny, S. (2011). Gender bias in leader selection? Evidence from a hiring simulation study. Sex Roles, 65, 234-242. https://doi.org/10.1007/s11199-011-0012-7.

Breaugh, J. A. (2008). Employee recruitment: Current knowledge and important areas for future research. Human Resource Management Review, 18, 103-118. https://doi.org/10.1016/j.hrmr.2008.07.003.

Casper, W. J., Wayne, J. H., \& Manegold, J. G. (2013). Who will we recruit? Targeting deep- and surface-level diversity with human resource policy advertising. Human Resource Management, 52, 311332. https://doi.org/10.1002/hrm.21530.

Cheryan, S., Plaut, V. C., Davies, P. G., \& Steele, C. M. (2009). Ambient belonging: How stereotypical cues impact gender participation in computer science. Journal of Personality and Social Psychology, 97, 1045-1060. https://doi.org/10.1037/a0016239.

Collins, M. W., \& Morris, S. B. (2008). Testing for adverse impact when sample size is small. Journal of Applied Psychology, 93, 463-471. https://doi.org/10.1037/0021-9010.93.2.463.

Cundiff, J. L., \& Vescio, T. K. (2016). Gender stereotypes influence how people explain gender disparities in the workplace. Sex Roles, 75, 126-138. https://doi.org/10.1007/s11199-016-0593-2.

De Corte, W. (2011). An integrated decision-aid for shaping recruitment and selection decisions. Paper presented at the EAWOP Small Group Meeting, June 22-24, Athens, Greece.

de Vries, R. E., Ashton, M. C., \& Lee, K. (2009). De zes belangrijkste persoonlijkheidsdimensies en HEXACO persoonlijkheidsvragenlijst [The six most important personality dimensions and the HEXACO personality inventory]. Gedrag en Organisatie, 22, 232-274.

Derous, E., \& Ryan, A. M. (2012). Documenting the adverse impact of resume screening: Degree of ethnic identification matters. International Journal of Selection and Assessment, 20, 464-474. https://doi.org/10.1111/ijsa.12009.

Derous, E., Ryan, A. M., \& Serlie, A. W. (2015). Double jeopardy upon resume screening: When Achmed is less employable than Aisha. Personnel Psychology, 68, 659-696. https://doi.org/10.1111/peps. 12078.

Else-Quest, N. M., \& Hyde, J. S. (2016). Intersectionality in quantitative psychological research: I. Theoretical and epistemological issues. Psychology of Women Quarterly, 40, 155-170. https://doi.org/10. 1177/0361684316629797.

Emerson, K. T. U., \& Murphy, M. C. (2014). Identity threat at work: How social identity threat and situational cues contribute to racial and ethnic disparities in the workplace. Cultural Diversity and Ethnic 
Minority Psychology, 20, 508-520. https://doi.org/10.1037/ a0035403.

Equal Employment Opportunity Commission, Civil Service Commission, Department of Labor, \& Department of Justice. (1978). Uniform guidelines on employee selection procedures. Retrieved from http://www.uniformguidelines.com/ uniformguidelines.html\#129.

European Commission. (2016). Report on equality between women and men in 2015. https://doi.org/10.2838/782115.

Garcia, M., Posthuma, R., \& Quiñones, M. (2010). How benefit information and demographics influence employee recruiting in Mexico. Journal of Business and Psychology, 25, 523-531. https://doi.org/ 10.1007/s10869-010-9175-4.

Gaucher, D., Friesen, J., \& Kay, A. C. (2011). Evidence that gendered wording in job advertisements exists and sustains gender inequality. Journal of Personality and Social Psychology, 101, 109-128. https://doi.org/10.1037/a0022530.

Guion, R. M. (2011). Assessment, measurement, and predictions for personnel decisions. East Sussex, UK: Routledge.

Güngör, G., \& Biernat, M. (2009). Gender bias or motherhood disadvantage? Judgments of blue collar mothers and fathers in the workplace. Sex Roles, 60, 232-246. https://doi.org/10.1007/s11199-008-95401.

Herriot, P. (1993). A paradigm bursting at the seams. Journal of Organizational Behavior, 14, 371-375. https://doi.org/10.1002/job. 4030140407.

Highhouse, S., \& Hoffman, J. R. (2001). Organizational attraction and job choice. International Review of Industrial and Organizational Psychology, 16, 37-64.

Highhouse, S., Thornbury, E. E., \& Little, I. S. (2007). Social-identity functions of attraction to organizations. Organizational Behavior and Human Decision Processes, 103, 134-146. https://doi.org/10. 1016/j.obhdp.2006.01.001.

Higuera, L. (2001). Adverse impact in personnel selection: The legal framework and test bias. European Psychologist, 6, 103-111. https://doi.org/10.1027//1016-9040.6.2.103.

Kamans, E., Gordijn, E. H., Oldenhuis, H., \& Otten, S. (2009). What I think you see is what you get: Influence of prejudice on assimilation to negative meta-stereotypes among Dutch Moroccan teenagers. European Journal of Social Psychology, 39, 842-851. https://doi. org/10.1002/ejsp.593.

Latu, I. M., Schmid Mast, M., \& Stewart, T. L. (2015). Gender biases in (inter)action: The role of interviewers' and applicants' implicit and explicit stereotypes in predicting women's job interview outcomes. Psychology of Women Quarterly, 39, 539-552. https://doi.org/10. 1177/0361684315577383.

Leary, M. R., \& Allen, A. B. (2011). Self-presentational persona: Simultaneous management of multiple impressions. Journal of Personality and Social Psychology, 101, 1033-1049. https://doi. org/10.1037/a0023884.

Lee, K., \& Ashton, M. C. (2004). Psychometric properties of the HEXACO personality inventory. Multivariate Behavioral Research, 39, 329-358. https://doi.org/10.1207/ s15327906mbr3902 8 .

Lee, K., \& Ashton, M. C. (2008). The HEXACO personality factors in the indigenous personality lexicons of English and 11 other languages. Journal of Personality, 76, 1001-1054. https://doi.org/10. 1111/j.1467-6494.2008.00512.x

McNab, S. M., \& Johnston, L. (2002). The impact of equal employment opportunity statements in job advertisements on applicants' perceptions of organizations. Australian Journal of Psychology, 54, 105409. https://doi.org/10.1080/00049530210001706573.

Newman, D. A., \& Lyon, L. S. (2009). Recruitment efforts to reduce adverse impact: Targeted recruiting for personality, cognitive ability, and diversity. Journal of Applied Psychology, 94, 298-317. https:// doi.org/10.1037/a0013472.
Newman, D. A., Jones, K. S., Fraley, R. C., Lyon, J. S., \& Mullaney, K. M. (2013). Why minority recruiting doesn't often work, and what can be done about it: Applicant qualifications and the 4-group model of targeted recruiting. In K. Y. T. Yu \& D. M. Cable (Eds.), The Oxford handbook of recruitment (pp. 492-526). New York: Oxford University Press.

Oostrom, J. K., \& Born, M. P. (2014). Using cognitive pretesting to explore causes for ethnic differences on role-plays. International Journal of Intercultural Relations, 41, 138-149. https://doi.org/10. 1016/j.ijintrel.2013.12.008.

Owuamalam, C. K., \& Zagefka, H. (2011). Downplaying a compromised social image: The effect of metastereotype valence on social identification. European Journal of Social Psychology, 41, 528-537. https://doi.org/10.1002/ejsp.805.

Owuamalam, C. K., \& Zagefka, H. (2014). On the psychological barriers to the workplace: When and why metastereotyping undermines employability beliefs of women and ethnic minorities. Cultural Diversity and Ethnic Minority Psychology, 20, 521-528. https:// doi.org/10.1037/a0037645.

Podsakoff, P. M., MacKenzie, S. B., Lee, J.-Y., \& Podsakoff, N. P. (2003). Common method biases in behavioral research: A critical review of the literature and recommended remedies. Journal of Applied Psychology, 88, 879-903. https://doi.org/10.1037/0021-9010.88.5. 879.

Purdie-Vaughns, V., Steele, C. A., Davies, P. G., Ditlmann, R., \& Crosby, J. R. (2008). Social identity contingencies: How diversity cues signal threat or safety for African Americans in mainstream institutions. Journal of Personality and Social Psychology, 94, 615-630. https:// doi.org/10.1037/0022-3514.94.4.615b.

Reeve, C. L., Highhouse, S., \& Brooks, M. E. (2006). A closer look at reactions to realistic recruitment messages. International Journal of Selection and Assessment, 14, 1-15. https://doi.org/10.1111/j.14682389.2006.00330.x.

Remedios, J. D., \& Snyder, S. H. (2015). How women of color detect and respond to multiple forms of prejudice. Sex Roles, 73, 371-383. https://doi.org/10.1007/s11199-015-0453-5.

Rubini, M., \& Menegatti, M. (2008). Linguistic bias in personnel selection. Journal of Language and Social Psychology, 27, 168-181. https://doi.org/10.1177/0261927X07313653.

Ryan, A. M., \& Tippins, N. T. (2004). Attracting and selecting: What psychological research tells us. Human Resource Management, 43, 305-318. https://doi.org/10.1002/hrm.20026.

Rynes, S. L. (1991). Recruitment, job choice, and post-hire consequences: A call for new research directions. In M. D. Dunnette \& L. M. Hough (Eds.), Handbook of industrial and organizational psychology (Vol. 2, 2nd ed., pp. 399-444). Palo Alto, CA: Consulting Psychologists Press.

Schmidt, J. A., Chapman, D. S., \& Jones, D. A. (2015). Does emphasizing different types of person-environment fit in online job ads influence application behavior and applicant quality? Evidence from a field experiment. Journal of Business and Psychology, 30, 267-282. https://doi.org/10.1007/s10869-014-9353-x.

Schuster, C., \& Martiny, S. E. (2017). Not feeling good in STEM: Effects of stereotype activation and anticipated affect on women's career aspirations. Sex Roles, 76, 40-55. https://doi.org/10.1007/s11199016-0665-3.

Semin, G. R. (2008). Language puzzles: A prospective retrospective on the linguistic category model. Journal of Language and Social Psychology, 27, 197-209. https://doi.org/10.1177/ $0261927 X 07313664$.

Semin, G., \& Fiedler, K. (1991). The linguistic category model, its bases, applications and range. European Review of Social Psychology, 2, $1-30$.

Stevens, C. D., \& Szmerekovsky, J. G. (2010). Attraction to employment advertisements: Advertisement wording and personality characteristics. Journal of Managerial Issues, 1, 107-126. 
Tajfel, H., \& Turner, J. C. (1986). The social identity theory of intergroup behavior. In S. Worchel \& W. G. Austin (Eds.), Psychology of intergroup relations (pp. 7-24). Chicago: Nelson-Hall.

Tippins, N. T. (2010). Adverse impact in employee selection procedures form the perspective of an organizational consultant. In J. L. Outtz (Ed.), Adverse impact. Implications for organizational staffing and high stakes selection (pp. 201-225). New York: Routledge.

Van de Vijver, F., \& Hambleton, R. K. (1996). Translating tests: Some practical guidelines. European Psychologist, 1, 89-99. https://doi. org/10.1027/1016-9040.1.2.89.

van Hooft, E. A. J., Born, M. P., Taris, T. W., \& Van der Flier, H. (2006). Ethnic and gender differences in applicants' decision-making processes: An application of the theory of reasoned action. International Journal of Selection and Assessment, 14, 156-166. https://doi.org/10.1111/j.1468-2389.2006.00341.x.

Volpone, S. D., Thomas, K. M., Sinisterra, P., \& Johnson, L. (2013). Targeted recruiting: Identifying future employees. In K. Y. T. Yu \& D. M. Cable (Eds.), The Oxford handbook of recruitment (pp. 492-526). New York: Oxford University Press.

Vorauer, J. D., Main, K. J., \& O'Connell, G. B. (1998). How do individuals expect to be viewed by members of lower status groups? Contents and implications of meta-stereotypes. Journal of Personality and Social Psychology, 75, 917-937. https://doi.org/ 10.1037/0022-3514.75.4.917.

Vorauer, J. D., Hunter, A., Main, K. J., \& Roy, S. A. (2000). Metastereotype activation: Evidence from indirect measures for specific evaluation concerns experienced by members of dominant groups in intergroup interaction. Journal of Personality and Social
Psychology, 78, 690-707. https://doi.org/10.1037/0022-3514.78.4. 690.

Walker, H. J., \& Hinojosa, A. S. (2013). Recruitment: The role of job advertisements. In K. Y. T. Yu \& D. M. Cable (Eds.), The Oxford handbook of recruitment (pp. 269-283). New York: Oxford University Press.

Walker, H. J., Feild, H. S., Giles, W. F., \& Bernerth, J. B. (2008). The interactive effects of job advertisements characteristics and applicant experiences on reactions to recruitment messages. Journal of Occupational and Organizational Psychology, 81, 619-638. https://doi.org/10.1348/096317907X252487.

Wayne, J. H., \& Casper, W. J. (2016). Why having a family-supportive culture, not just policies, matters to male and female job seekers: An examination of work-family conflict, values, and self-interest. Sex Roles, 75, 459-475. https://doi.org/10.1007/s11199-016-0645-7.

Wessel, J. L., Hagiwara, N., Ryan, A. M., \& Kermond, C. M. Y. (2015). Should women applicants "man up" for traditionally masculine fields? Effectiveness of two verbal identity management strategies. Psychology of Women Quarterly, 39, 243-255. https://doi.org/10. 1177/0361684314543265.

Windsheid, L., Bowes-Sperry, L., Kidder, D. L., Cheung, H. K., Morner, M., \& Lievens, F. (2016). Actions speak louder than words: Outsiders' perceptions of diversity mixed messages. Journal of Applied Psychology, 101, 1329-1341. https://doi.org/10.1037/ ap10000107.

Zedeck, S. (2010). Adverse impact: History and evolution. In J. L. Outtz (Ed.), Adverse impact: Implications for organizational staffing and high sakes selection (pp. 3-27). New York: Routledge. 